\title{
Analysis of Erosion Rate on Discharge Slurry HDPE Pipe in Canal Water Intake PLTGU Grati using CFD Simulation
}

\author{
Agoes Santoso ${ }^{1}$, Bahrul $\mathrm{Ilmi}^{2}$
}

\begin{abstract}
The dredging of the canal water intake at PLTGU Grati is an effort to maintain the depth of the reduced canal due to sedimentation. The dredging process itself uses a cutter suction dredger. To distribute mud or slurry (a mixture of water and sand) result of dredging to dumping area of PLTGU Grati using HDPE (high-density polyethylene), as pipe material, hence pipe does not wear due to corrosion but erosion. Basically, erosion is caused by impact of solid particle (sand) which is suspended inflow (multiphase) on a solid wall boundary. Wear caused by erosion itself is recognized as one of the problems in some industries that distribute slurry in their process. This research thesis analyzes and predicts the rate of erosion occurring in HDPE pipes that are transported slurry from the sedimentation dredging in PLTGU Grati using CFD (computational fluid dynamic) method. Variations of slurry concentration, impact angle, particle diameter and velocity of the slurry has been be performed to determine the effect on the rate of erosion. The results of this research thesis showed that the concentration of slurry, impact angel, diameter of particle and the concentration of the slurry were directly proportional to the rate of erosion on the HDPE pipe.
\end{abstract}

Keywords - erosion rate, cutter suction dredger, HDPE, CFD, slurry, multiphase flow

\section{INTRODUCTION}

$\mathrm{E}$

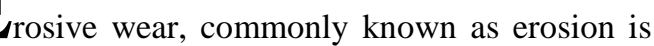
defined as a material loss resulting from the impact of solid particles on the material surface [1]. Erosion wear is recognized as a problem in slurry transportation equipment such as pipes and pump. Dredging in canal water intake PLTGU Grati is one the process that transport slurry from the bottom of the canal to dumping area using cutter suction dredger. This research thesis analyzes and predicts the rate of erosion occurring in HDPE pipes that are transported slurry from the sedimentation dredging in PLTGU Grati using CFD (computational fluid dynamic) method. Variations of slurry concentration, impact angle, particle diameter and velocity of the slurry has been be performed to determine the effect on the rate of erosion [1-10].

Technically dredging is the process of moving underwater sediments for the purpose of maintaining river channels, lakes, reservoirs, water intake canals, and sea lanes on docks or for mining purposes. Dredging at this time has been very well developed in the process of implementation and the method used. To undertake underwater sediment dredging activities requires the assistance of dredgers. Dredges have various types such as suction dredgers and suction hoppers dredger [1, 613].

The cutter suction dredger is one type of dredger. The working system of the cutter suction dredger is by cutting the material from the bottom of the water which has been crushed by the rotating cutter head after which the sediment that has been eroded by the cutter head has

\footnotetext{
${ }^{1}$ Agoes Santoso, Department of Marine Engineering, Institut Teknologi Sepuluh Nopember, Surabaya 60111, Indonesia, E-mail agoes@its.ac.id

${ }^{2}$ Bahrul Ilmi, Department of Marine Engineering, Institut Teknologi Sepuluh Nopember, Surabaya 60111, Indonesia, E-mail ilmi14@mhs.ne.its.ac.id
}

been be pumped using a centrifugal pump to the dumping area to be distributed through the pipe.

As a result of the distribution of sediment mixture with water (slurry) causes erosion on the inner side of the HDPE (high-density polyethylene) discharge pipe. Erosion itself is the loss of material due to the impact or impact of particles on a material surface. Therefore it is necessary to note the rate of erosion to predict the age of the discharge pipe. In addition, there should also be a review of the installation on the discharge pipe that is installed in turn to the rate of erosion. So as to minimize damage to the discharge pipe to save costs. In this final project has been be an analysis of the rate of erosion that occurs on the discharge pipe type HDPE suction dredger using computational fluid dynamics (CFD) simulation.

Computational fluid dynamics (CFD) is a set of methodologies that use computers to simulate fluid flow, heat transfer, chemical reactions, and other flow phenomena by solving numerical Navier-Stokes equations. And one of the phenomena that can be simulated by this method is predicting the rate of erosion. Although modeling erosion through CFD has been done over the years, there is still a need for more in-depth knowledge of available models and methods [14-15].

\section{A. Erosion}

Basically, Erosion is caused by the impact of a solid particle (sand) which is suspended in flow (multiphase flow) on a solid wall or boundary [2]. With different influencing factors on erosion from sand particles, different types of wear mechanisms can occur. Before going deeper into the types of wear relevant for this thesis, a list of some relevant wear mechanisms from particle impacts is listed in table 1 . 
DIFFERENT TYPE OF WEAR FORM SAND AND PARTICLES [3]

\begin{tabular}{|c|c|c|}
\hline Mechanism of erosion & Definition & Illustration \\
\hline Abrasive erosion & $\begin{array}{l}\text { Particles strike the wall at low impact } \\
\text { angles and material is removed by } \\
\text { cutting. The particles act like a bed that } \\
\text { is sliding over the surface. }\end{array}$ & $\begin{array}{l}\text { Low impact } \\
\text { angle }\end{array}$ \\
\hline Fatigue wear & $\begin{array}{l}\text { Particles strike the surface at low } \\
\text { speed, but a with a large impact angle. } \\
\text { The surface material cannot be } \\
\text { plastically deformed, but it becomes } \\
\text { weak due to fatigue action. After } \\
\text { repeated hits, cracks has been occur in } \\
\text { the material and particles has been be } \\
\text { detached from the surface after } \\
\text { multiple hits }\end{array}$ & $\begin{array}{ll} & \text { High impact } \\
0 & \text { angle } \\
0 & \text { Low speed }\end{array}$ \\
\hline Brittle fracture & $\begin{array}{l}\text { Erosion by brittle fracture when } \\
\text { particles hit the wall with medium } \\
\text { velocity and high impact angle. This is } \\
\text { likely to happen when the particles } \\
\text { have sharp edges }\end{array}$ & $\begin{array}{l}\text { High impact } \\
\text { angle } \\
\text { Medium speed }\end{array}$ \\
\hline Saltation wear & $\begin{array}{l}\text { Transport of a sediment where particles } \\
\text { are moved forward along the pipe in } \\
\text { series, bouncing along the wall. }\end{array}$ & \\
\hline
\end{tabular}

\section{B. Slurry}

Slurries are a solid-liquid mixture with a large number of solids. A slurry can sometimes be classified as a highly viscous fluid. Since the particle concentration is high, it is important to understand the physical principles for this type of flow and also to classify the slurries. With the high particle concentration, the erosion phenomena has been occur. Slurry erosion is an erosion mechanism that occurs due to the wall shear of the slurry flow through a pipe combined with random particle impacts $[1,4]$.

It is important to classify a slurry in order to provide a basis for describing the physical appearance and the flow behavior of the two-phase solid-liquid mixture, i.e. rheology. Rheology is the study of the flow of matter and applies to substances with complex structures such as slurries. The rheology is a dynamic property of the microstructure of the slurry and is affected by various attributes such as the shape, density, size and mass fraction of the suspended solid particles and the density and viscosity of the carrier fluid [4].

The Density of the slurry is affected by the density of the carrier fluid, the density of the solid particles and the concentration of solid particles present. The solid concentration can be expressed by volume or weight fraction $[4,5]$. The relationship between these two can be expressed by $[4,5]$ as:

$$
C_{V}=\frac{C_{w} \rho_{m}}{\rho_{s}}=\frac{100 \frac{C_{w}}{\rho_{s}}}{\frac{C_{w}}{\rho_{s}}+\frac{100-C_{w}}{\rho_{l}}}
$$

\footnotetext{
where

$\mathrm{C}_{\mathrm{V}} \quad=$ concentration by volume [\%]

$\mathrm{C}_{\mathrm{W}} \quad=$ concentration of solids by weight [\%]

$\rho_{m} \quad=$ density of mixture $\left[\mathrm{kg} / \mathrm{m}^{3}\right]$
}

$$
\begin{array}{ll}
\rho_{s} & =\text { density of solid }\left[\mathrm{kg} / \mathrm{m}^{3}\right] \\
\rho_{l} & =\text { density of liquid }\left[\mathrm{kg} / \mathrm{m}^{3}\right]
\end{array}
$$

Water flowing around solid particles creates pressure differentials around them and the resulting drag forces move the particles in the general direction of the flow. The velocity of the solids is slower than that of the water. This is called slippage and particles of different sizes and densities have different slippages. Relative to horizontal flow, slippage increases in uphill flow and decreases in downhill flow because gravity slows down and respectively accelerates the flow of solids relative to the liquid. It follows that, in various parts of a convoluted pipeline, local solids concentrations vary, which influences local slurry velocities, pipe wear, and friction losses. [1,4,5]

When the sizing, density, and concentration of solids in a slurry are known, we must determine the average Limiting settling velocity $\left(\mathrm{V}_{\mathrm{L}}\right)$ of the slurry, which has been move the solids and not let them settle. Limiting settling velocity defined $[4,5]$ as:

$$
V_{L}=F_{L} \sqrt{2 g D \frac{\left(S-S_{I}\right)}{S_{I}}}
$$

$$
\mathrm{FL}=0.4794+\left(0.5249 \mathrm{X}\left(0.01 \mathrm{C}_{\mathrm{v}}\right)^{0.1058} \mathrm{X}\left(\log \left(\mathrm{d}_{50}\right)-1\right)\right.
$$

$$
\begin{array}{ll}
\text { where } & \\
\mathrm{V}_{\mathrm{L}} & =\text { limiting settling velocity }[\mathrm{m} / \mathrm{s}] \\
\mathrm{F}_{\mathrm{L}} & =\text { settling velocity factor } \\
\mathrm{g} & =\text { gravitational constant }\left[\mathrm{m} / \mathrm{s}^{2}\right] \\
\mathrm{D} & =\text { inside pipe diameter }[\mathrm{m}] \\
\mathrm{S} & =\text { specific gravity of particle } \\
\mathrm{S}_{1} & =\text { specific gravity of fluid } \\
\mathrm{C}_{\mathrm{v}} & =\text { concentration by volume }[\%] \\
\mathrm{d}_{50} & =\text { average particle size }[\mu \mathrm{m}]
\end{array}
$$




\section{METHOD}

The methodology used in this research is a simulation-based method, which has been be tested using software for problem-solving. The erosion rate on the pipe has been be simulated by CFD (computational fluid dynamics) method.

\section{A. Data Collection}

In this section, we has been present the data that have been obtained to support the modeling and simulation process.

The interpolation has been be performed for unknown data. After the interpolation obtained data as follows on table 1 - table 7: for the HDPE pipe used to

TABLE 2 .

CUTTER SUCTION DREDGER SPECIFICATION

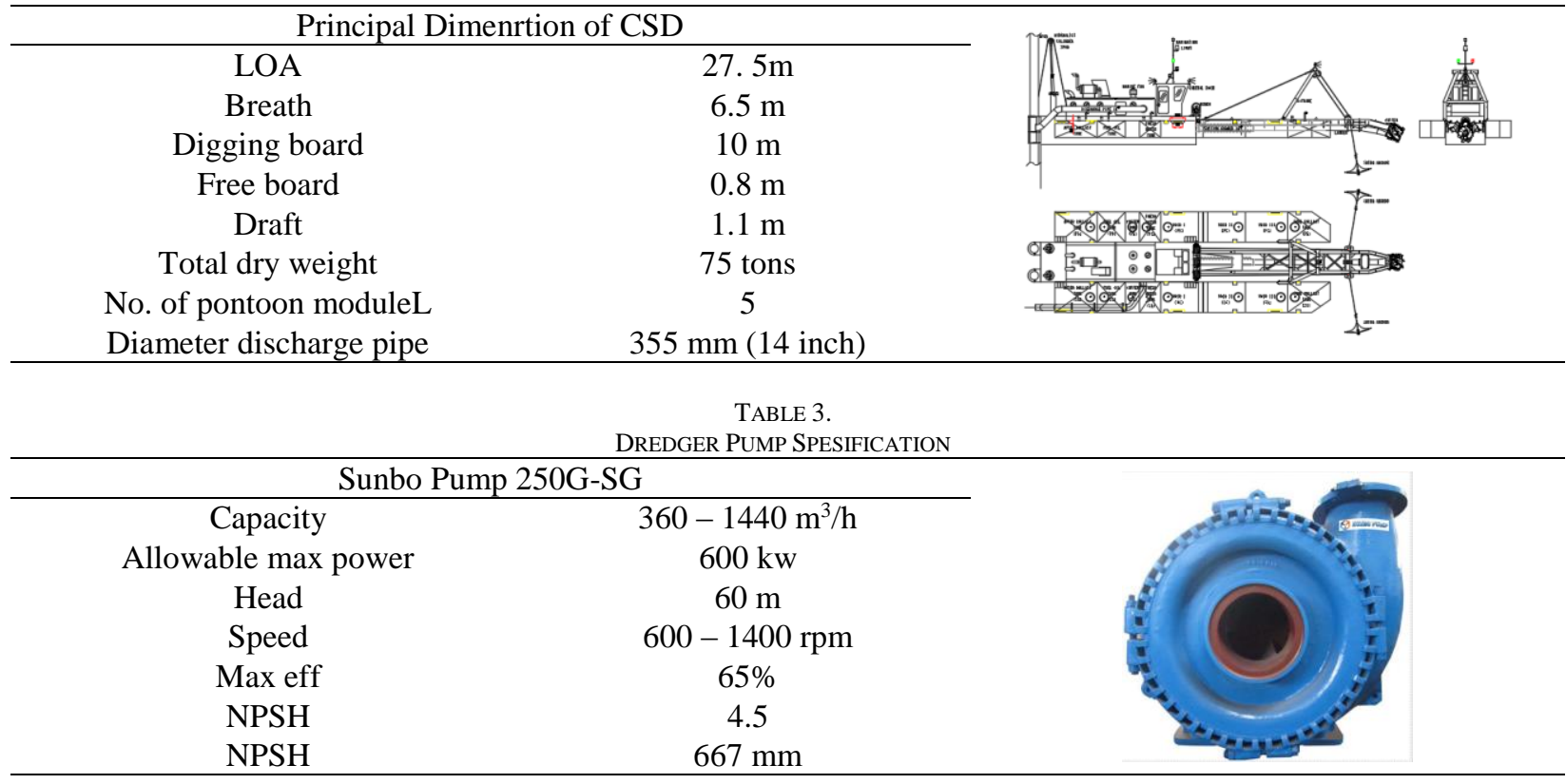

TABLE 4.

CLEAR WATER PUMP PERFORMANCE

\begin{tabular}{cccc}
\hline Rpm & Capacity discharge $\left[\mathrm{m}^{3} / \mathrm{h}\right]$ & Engine load $[\%]$ \\
1000 & 884.9 & 61 \\
1100 & 1061.9 & 63 \\
1200 & 1287.1 & 70 & 73 \\
1300 & 1318.7 & 84 & \\
1400 & 1377.1 & 1
\end{tabular}

TABLE 5.

Mud/Slurry (Cw 80\%) Pump Performance

\begin{tabular}{ccc}
\hline $\mathrm{Rpm}$ & Capacity discharge $\left[\mathrm{m}^{3} / \mathrm{h}\right]$ & Engine load $[\%]$ \\
1000 & 897.9 & 52 \\
1100 & 1034.4 & 55 \\
1200 & 1105.0 & 63 \\
1300 & 1228.7 & 68 \\
1400 & 1352.1 & 87 \\
\hline
\end{tabular}

TABLE 6 .

PUMP PERFORMANCE ON VARETY SLURRIES

\begin{tabular}{ccc}
\hline Rpm & Cw & Capacity $\left(\mathrm{m}^{3} /\right.$ hour $)$ \\
\hline 1400 & $0 \%$ & 1377.1 \\
1400 & $20 \%$ & 1370.85 \\
1400 & $40 \%$ & 1354.6 \\
1400 & $60 \%$ & 1358.35 \\
1400 & $80 \%$ & 1352.1 \\
\hline
\end{tabular}

This research has been use pump discharge data $\left(\mathrm{m}^{3} / \mathrm{h}\right)$ at $1400 \mathrm{rpm}$ and five sand mass concentration $(\mathrm{Cw})$ on slurry ie (Cw: 0\%; 20\%; 40\%; 60\%; 80\%. Since the data were taken at commissioning is only underwater conditions transmit the slurry is a 16 inch HDPE pipe SDR 11 (PN 16) which has the following specifications on table 7. 
TABLE 7

HDPE PIPE SPECIFICATION

\begin{tabular}{ll}
\hline Material & PE 100 \\
\hline Outside diameter & $355 \mathrm{~mm}$ \\
Thickness & $32.2 \mathrm{~mm}$ \\
Density & $950 \mathrm{~kg} / \mathrm{m}^{3}$ \\
Max Pressure & $16 \mathrm{bar}$ \\
\hline
\end{tabular}

\section{B. Calculating Limiting Settling Velocity}

Limiting settling velocity is the rate at which solid particles in the slurry has been undergo deposition at the bottom of the pipe. Therefore, in the planning of piping system that carries slurry, it is necessary to calculate limiting settling velocity. Using equation $2 \& 3$ the result of calculation as shown in table 8 .

TABLE 8

LIMITING SETTLING VELOCITY

\begin{tabular}{|c|c|c|c|}
\hline \multicolumn{4}{|c|}{$\mathrm{D}_{50}=20 \mu \mathrm{m} 8$} \\
\hline $\mathrm{Cw}(\%)$ & $\mathrm{Cv}(\%)$ & $\mathrm{F}_{\mathrm{L}}$ & $\mathrm{V}_{\mathrm{l}}(\mathrm{m} / \mathrm{s})$ \\
\hline 0 & 0 & 0.4794 & 1.5183 \\
\hline 20 & 8.817 & 0.60579 & 1.9186 \\
\hline 40 & 20.5 & 0.61760 & 1.956 \\
\hline 60 & 36.71 & 0.626 & 1.983 \\
\hline 80 & 60.740 & 0.63443 & 2.0093 \\
\hline \multicolumn{4}{|c|}{$\mathrm{D}_{50}=50 \mu \mathrm{m}$} \\
\hline $\mathrm{Cw}(\%)$ & $\mathrm{Cv}(\%)$ & $\mathrm{F}_{\mathrm{L}}$ & $\mathrm{V}_{1}(\mathrm{~m} / \mathrm{s})$ \\
\hline 0 & 0 & 0.4794 & 1.5183 \\
\hline 20 & 8.817 & 0.77289 & 2.4478 \\
\hline 40 & 20.5 & 0.80029 & 2.5346 \\
\hline 60 & 36.716 & 0.8207 & 2.5992 \\
\hline 80 & 60.740 & 0.83937 & 2.6584 \\
\hline \multicolumn{4}{|c|}{$\mathrm{D}_{50}=80 \mu \mathrm{m}$} \\
\hline $\mathrm{Cw}(\%)$ & $\mathrm{Cv}(\%)$ & $F_{L}$ & $\mathrm{~V}_{1}(\mathrm{~m} / \mathrm{s})$ \\
\hline 0 & 0 & 0.4794 & 1.5183 \\
\hline 20 & 8.817 & 0.8586 & 2.7193 \\
\hline 40 & 20.5 & 0.894 & 2.8314 \\
\hline 60 & 36.716 & 0.9204 & 2.9149 \\
\hline 80 & 60.740 & 0.9445 & 2.9913 \\
\hline \multicolumn{4}{|c|}{$\mathrm{D}_{50}=140 \mu \mathrm{m}$} \\
\hline $\mathrm{Cw}(\%)$ & $\mathrm{Cv}(\%)$ & $\mathrm{F}_{\mathrm{L}}$ & $\mathrm{V}_{1}(\mathrm{~m} / \mathrm{s})$ \\
\hline 0 & 0 & 0.4794 & 1.5183 \\
\hline 20 & 8.817 & 0.9606 & 3.0425 \\
\hline 40 & 20.5 & 1.0056 & 3.1848 \\
\hline 60 & 36.716 & 1.039 & 3.2908 \\
\hline 80 & 60.740 & 1.0697 & 3.3877 \\
\hline
\end{tabular}

The value of limiting settling velocity is directly proportional to the value of settling velocity factor, $\mathrm{Cw}$, $\mathrm{Cw}$, and solid particle diameter (sand) in the slurry. The largest limiting settling velocity when the slurry $\mathrm{Cw}$ is $80 \%$ and the sand diameter of $140 \mu \mathrm{m}$ is $3.3877 \mathrm{~m} / \mathrm{s}$.

\section{Calculation Mass flow}

The mass flow rate of the sand particles in the slurry becomes one of the insert values in modeling the erosion rate in ANSYS Fluent. There are two types of mass flow rates in the slurry that is the mass flow rate in the liquid phase (water) and the solid phase (sand). In this sub-chapter has been be calculated the mass flow rate of sand on the concentration of weight slurry $(\mathrm{Cw})$ variation $0 \%, 20 \%, 40 \%, 60 \%$, and $80 \%$. The equation for calculating the mass flow rate based on [14-15]. The results shown in figure 1 - figure 7 and table 9 - table 10 .

$$
\dot{\mathrm{m}}=\rho \mathrm{VA}
$$

where:

$$
\begin{array}{ll}
\dot{\mathrm{m}} & =\text { mass flow }[\mathrm{kg} / \mathrm{s}] \\
\rho & =\text { density }\left[\mathrm{kg} / \mathrm{m}^{3}\right] \\
\mathrm{V} & =\text { Velocity }[\mathrm{m} / \mathrm{s}] \\
\mathrm{A} & =\text { Area }\left[\mathrm{m}^{2}\right]
\end{array}
$$




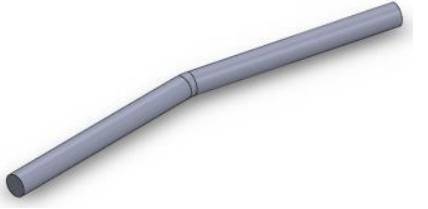

Figure 1. 3D model pipe bend $15^{\circ}$

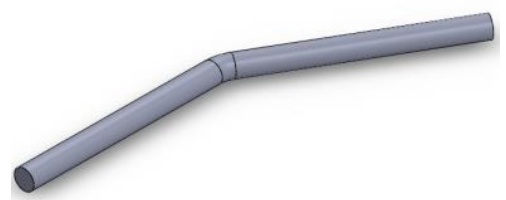

Figure 2. 3D model pipe bend $30^{\circ}$

Figure 3. 3D model pipe bend $45^{\circ}$

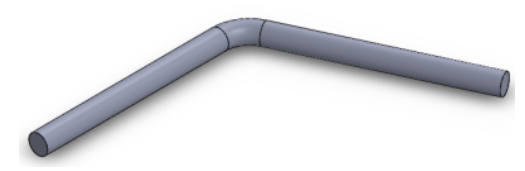

Figure 4. 3D model pipe bend $60^{\circ}$

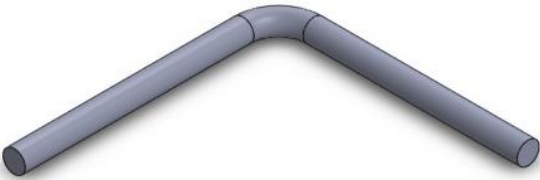

Figure 5. 3D model pipe bend $90^{\circ}$

TABLE 9

LIMITING SETTLING VELOCITY

\begin{tabular}{ccccc}
\hline $\mathrm{Cw}(\%)$ & $\mathrm{Cv}(\%)$ & $\mathrm{Q}\left(\mathrm{m}^{3} / \mathrm{h}\right)$ & $\mathrm{V}(\mathrm{m} / \mathrm{s})$ & $\begin{array}{c}\dot{\mathrm{m}} \mathrm{sand} \\
(\mathrm{kg} / \mathrm{s})\end{array}$ \\
\hline 0 & 0 & 1377.1 & 4.672 & 0 \\
20 & 8.979 & 1370.85 & 4.65 & 88.90 \\
40 & 20.844 & 1364.6 & 4.62 & 205.43 \\
60 & 37.228 & 1358.35 & 4.60 & 365.22 \\
80 & 61.288 & 1352.1 & 4.58 & 598.43 \\
\hline
\end{tabular}

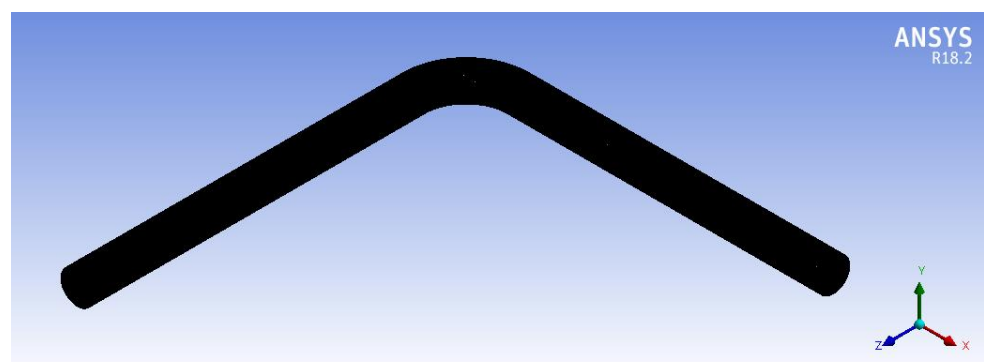

Figure 6. Meshing on pipe $90^{\circ}$ bend

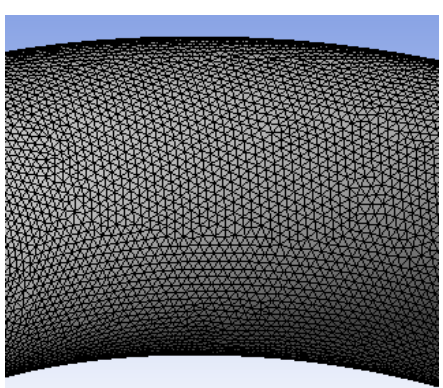

Figure 7. Detail mesh on bend

TABLE 10.

DETAIL MESH

Detail Mesh

\begin{tabular}{ll}
\hline Size function & Prox. and curvature \\
Relevance centre & Fine \\
Smoothing & High \\
Min size & $0.777 \mathrm{~mm}$ \\
Element size & $10 \mathrm{~mm}$ \\
Nodes & 638305 \\
Elements & 1976429 \\
\hline
\end{tabular}


Calculation results of slurry speed and mass flow rate of sand in the slurry in some conditions can be seen in table 8 .

D. Pre-Processing (Geometry and Meshing)

A three-dimensional modeling process of five samples of a 6 meter long HDPE pipe having an internal diameter of $322.8 \mathrm{~mm}$. Modeling uses the swept feature to form the turning angle of the model.

\section{E. Processing}

In this step determine the multiphase model in slurry ie DPPM model (discrete dense phase model) one main phase of continuous fluid and one discrete phase shon in table 11 .

TABLE 11

SIMULATION PARAMETER

\begin{tabular}{lll}
\hline Multiphase Model & Multiphase model & Eulerian \\
\cline { 2 - 3 } & Eulerian parameter & DDPM \\
\hline Fluid & Fluid & Water \\
\cline { 2 - 3 } & Fluid viscosity & $1.003 \mathrm{e}^{-3} \mathrm{~kg} / \mathrm{ms}$ \\
\cline { 2 - 3 } & Fluid density & $1025 \mathrm{~kg} / \mathrm{m}^{3}$ \\
\hline Solid Particle & Solid & Sand \\
\cline { 2 - 3 } & Density & $2650 \mathrm{~kg} / \mathrm{m}^{3}$ \\
\cline { 2 - 3 } & Diameter [mm] & $0.05 ; 0.08 ; 0.1 ; 0.14$ \\
\hline Turbulence model & Turbulence model & Realizable $\mathrm{k}-\varepsilon$ \\
\cline { 2 - 3 } & Wall functions & Scalable \\
\hline Wall & Wall & HDPE \\
\cline { 2 - 3 } & Density & $950 \mathrm{~kg} / \mathrm{m}^{3}$ \\
\hline Boundary Conditions & Inlet mass flow $[\mathrm{kg} / \mathrm{s}]$ & $0 ; 88.97 ; 205.92 ; 367.13 ;$ \\
& & 604.55 \\
\cline { 2 - 3 } & Wall boundary & No slip \\
\cline { 2 - 3 } & Erosion model & generic \\
\hline
\end{tabular}

The boundary conditions are then set on the inlet (velocity inlet), wall (wall), and outlet (pressure outlet). For inlet conditions, it is necessary to determine the speed and mass flow.

\section{F. Post Processing}

After completing the process of solver/processing on the model. Then it has been get the value of erosion rate and contour of erosion rate value on the pipe bend. Table 12 Shows contours and the value of the rate of erosion. The value of the highest erosion rate at the time the pipe is applied with the $61.28 \%$ slurry $\mathrm{Cv}$ value has a maximum erosion rate of $8.54 \mathrm{e}-07 \mathrm{~kg} / \mathrm{m} 2 \mathrm{~s}$. And erosion does not occur on clean water. The value has been be converted to ( $\mathrm{mm} / \mathrm{year})$ by the multiplication of the density value of the HDPE pipe and unit investigation.

Figure 8. shows the contour of the erosion rate at the pipe with pipe bend $90^{\circ}$ and $\mathrm{Cv} 36.72 \%$ slurry simulated with four different sand diameter. This aims to determine the relationship of erosion rate to slurry sand diameter.

Figure 9. shows the contour of the erosion rate at the pipe with pipe bend $90^{\circ}$ and $\mathrm{Cv} 36.72 \%$ slurry simulated with four different speeds. This aims to determine the relationship of erosion rate to slurry speed

\section{RESULT AND DISCUSSIONS}

The result of the simulation has been be displayed on graphic and table to make it easier to analyze. Figure 10 shows that the volume concentration of slurry $(\mathrm{Cv})$ is directly proportional to the rate of erosion at relatively similar velocities. The greater the volume content of the solid particles (sand) in the slurry the higher the rate of erosion. It can be seen that the highest erosion rate is highest at $\mathrm{Cv}$ of $60.74 \%$ and the bend angle of pipe $90^{\circ}$ is $27.22 \mathrm{~mm} /$ year. While in the clear water, erosion do not occur. From figure 11 can be seen the effect impact angle on the HDPE pipe that was transported slurry. The impact angle of the pipe is directly proportional to the rate of erosion it can be seen on the graph showing that on all four slurry variations which all increase in erosion rate. The value of the maximum erosion rate at the turning angle of the pipe $90^{\circ}$ is at $\mathrm{Cv} 8.82 \%$ of $6.47 \mathrm{~mm} /$ year, $\mathrm{Cv} 20.5 \%$ of 12.23 $\mathrm{mm} /$ year, Cv $36.72 \%$ of $19.13 \mathrm{~mm} /$ year and $\mathrm{Cv} 60.74 \%$ of $27.22 \mathrm{~mm} /$ year. Figure 12 shows the relationship of the large diameter of solid particles (sand) in the slurry that is directly proportional to erosion rate. The highest erosion rate is $19.32 \mathrm{~mm} /$ year when sand is $0.14 \mathrm{~mm}$ in diameter. and nil the lowest rate of erosion at the time of sand on the slurry $0.05 \mathrm{~mm}$ in diameter ie 10.66 $\mathrm{mm} /$ year. 


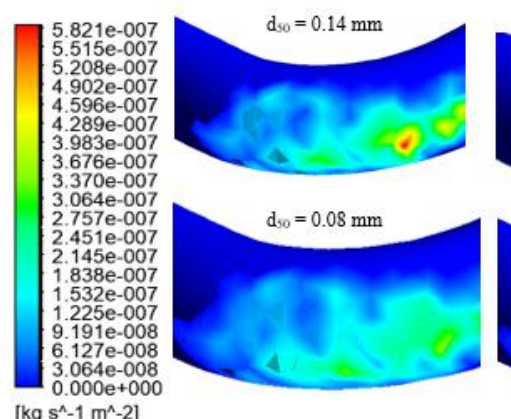

Figure 8

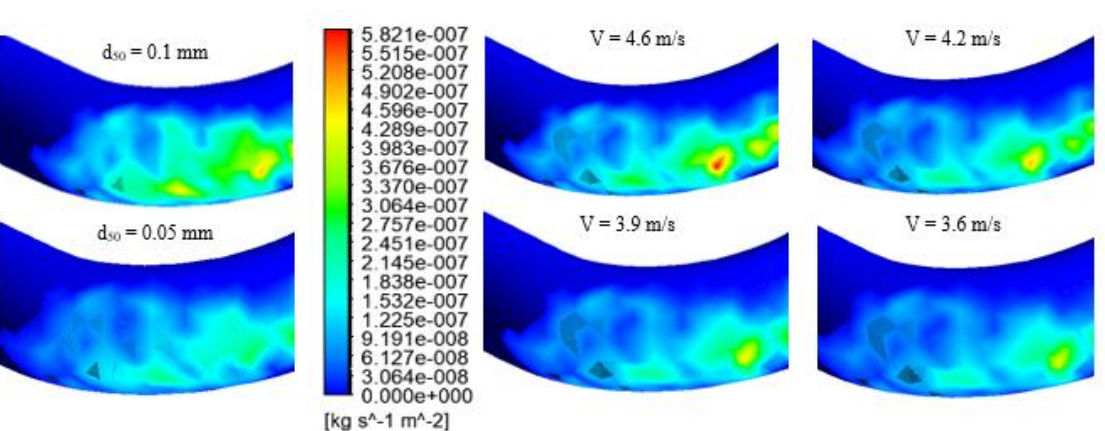

Figure 9.

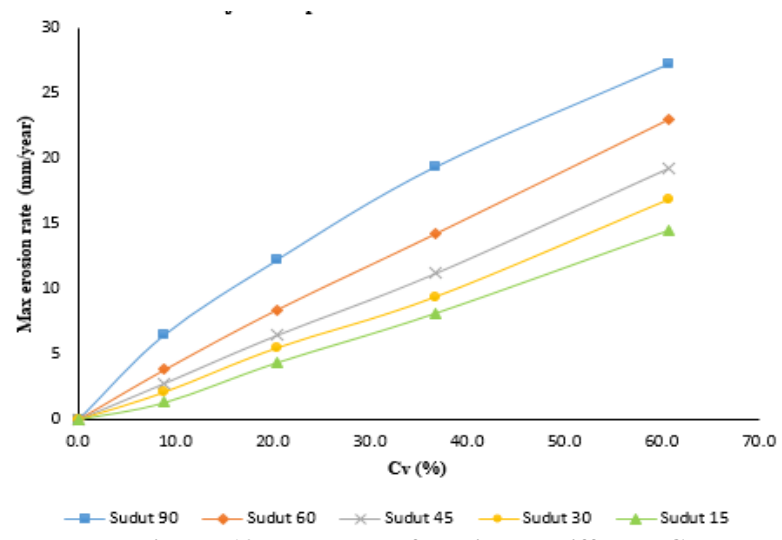

Figure 10. The trend of erosion on different $\mathrm{Cv}$

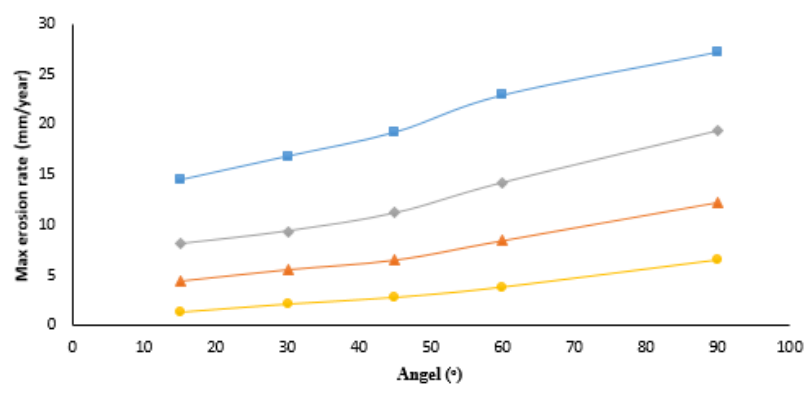

$\rightarrow-\mathrm{cv} 60.74 \% \rightarrow \mathrm{cv} 36.72 \rightarrow \mathrm{cv} 20.5 \% \rightarrow \mathrm{cv} 8.82$

Figure 11. The trend of erosion on different angel bind pipe

TABLE 12

EROSION RATE ON VARIATION SAND DIAMETER Angle 90; Cv 36.72\%; Cw 60\%

\begin{tabular}{|c|c|c|c|}
\hline \multicolumn{4}{|c|}{ Angle $90 ; \mathrm{Cv} 36.72 \% ; \mathrm{Cw} 60 \%$} \\
\hline $\mathrm{d}_{50}(\mathrm{~mm})$ & $\mathrm{V}(\mathrm{m} / \mathrm{s})$ & $\begin{array}{c}\text { Max } \\
\text { erosion } \\
\text { rate } \\
\left(\mathrm{kg} / \mathrm{m}^{2} \mathrm{~s}\right)\end{array}$ & $\begin{array}{c}\text { Max } \\
\text { erosion } \\
\text { rate } \\
\text { (mm/year) }\end{array}$ \\
\hline 0.05 & 4.6 & $3.21 \mathrm{E}-07$ & 10.6558 \\
\hline 0.08 & 4.6 & 4.64E-07 & 15.4028 \\
\hline 0.1 & 4.6 & $5.32 \mathrm{E}-07$ & 17.6602 \\
\hline 0.14 & 4.6 & $5.82 \mathrm{E}-07$ & 19.3199 \\
\hline
\end{tabular}

TABLE 13

EROSION RATE ON VARIATION SAND DIAMETER

\begin{tabular}{c|c|c|c}
\hline \multicolumn{4}{c}{ EROSION RATE ON VARIATION SAND DIAMETER } \\
\hline \multicolumn{4}{c}{ Angle $90^{\circ} ; \mathrm{Cv} 36.72 \% ; \mathrm{Cw} 60 \%$} \\
$\mathrm{~V}(\mathrm{~m} / \mathrm{s})$ & $\mathrm{d}_{50}(\mathrm{~mm})$ & $\begin{array}{c}\text { Max erosion } \\
\text { rate }\left(\mathrm{kg} / \mathrm{m}^{2} \mathrm{~s}\right)\end{array}$ & $\begin{array}{c}\text { Max erosion } \\
\text { rate } \\
(\mathrm{mm} / \mathrm{year})\end{array}$ \\
3.6 & 0.14 & $3.94 \mathrm{E}-07$ & 13.0791 \\
3.9 & 0.14 & $4.46 \mathrm{E}-07$ & 14.8016 \\
4.2 & 0.14 & $5.14 \mathrm{E}-07$ & 17.0526 \\
4.6 & 0.14 & $5.82 \mathrm{E}-07$ & 19.3199 \\
\hline
\end{tabular}

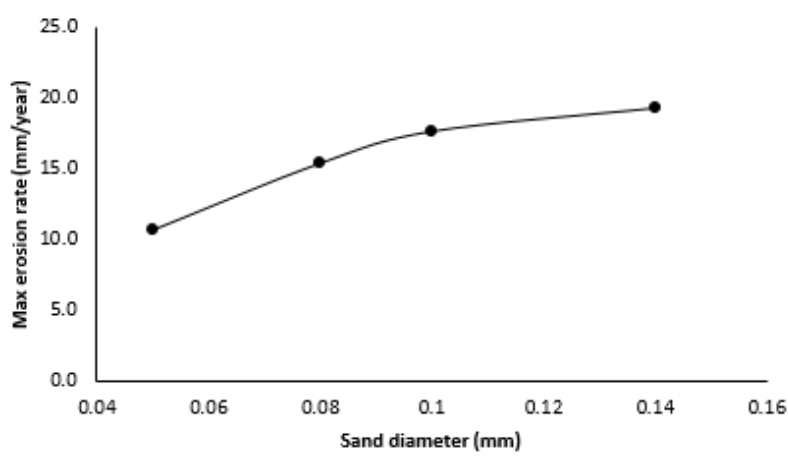

Figure 12. The trend of erosion on different angel bind pipe

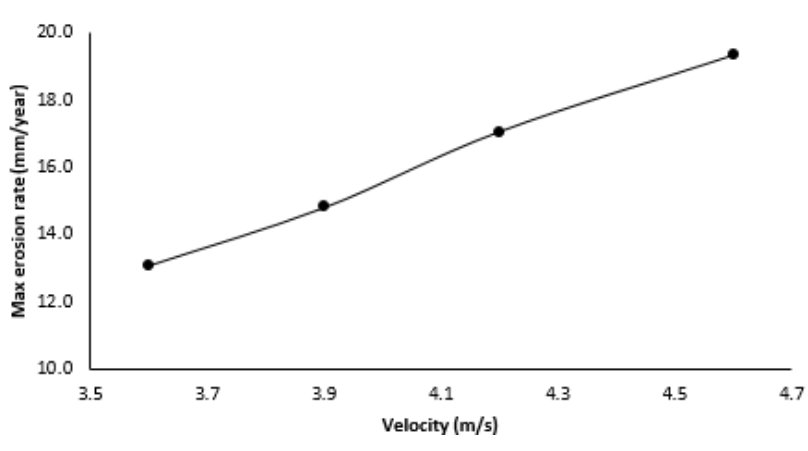

Figure 13. The trend of erosion on different velocity 
Figure 10 - 13 and table $12-13$ shows that the relationship between slurry speed and erosion rate is directly proportional. From the graph also concluded that the greater the speed of slurry then the rate of erosion experienced by the angle on the pipe is also higher. It can be seen that the highest erosion rate is experienced at the highest speed at $4.6 \mathrm{~m} / \mathrm{s}$ with a maximum erosion rate of $19.32 \mathrm{~mm} /$ year. Increased fluid velocity (water) can lead to a considerable increase in the rate of erosion when the particle (sand) velocity is close to or equal to the fluid velocity.

\section{CONCLUSION}

From the research that has been done and discussed it can be concluded that:

1. The rate of erosion on the HDPE pipe carrying the slurry is directly proportional to the slurry concentration $(\mathrm{Cv} / \mathrm{Cw})$.

2. The largest erosion rate occurs when the concentration of volume $60.74 \%$ slurry or $\mathrm{Cw}$ (concentration of weight) $80 \%$ and the angel of bending pipe $90^{\circ}$, which is equal to 27.22 $\mathrm{mm} /$ year.

3. The speed of the slurry and particle diameter is directly proportional to the rate of erosion experienced by the pipe

\section{REFERENCES}

[1] DNV, "Recommended Practice RPO501 Erosive Wear In Piping System," p. 10, 2007.

[2] Y. Oka, H. Omolgi, H. Hosokawa and M. Matsumura, "The Impact angel dependence of erosion damage caused by solid particle," Wear, Vols. 203-204, pp. 573-579, 1997.

[3] H. Meng and K. Ludena, "'Wear models and predictive equations: their form and content," Wear, Vols. 181-183, pp. 443-457, 1995.

[4] E. j. Wasp, "Solid-liquid Flow - Slurry Pipeline Transportation Series on Bulk," vol. 1, 1977.

[5] WARMAN, "Slurry Pumping Manual," A Technical Application Guide For Users Of Centrifugal Slurry Pumps And Slurry Pumping Systems, 2002.

[6] R. Wood, T. Miles, and J. Ganeshalingham, "Upstream swirl induction for reduction of erosion damage from slurries in pipeline bend," ear, vol. 25, pp. 770-778, 2001.

[7] Y. Oka and T. Yoshida, "Practical Estimation of Erosion Damage Caused by Solid Particle Impact. Part 2: Mechanical Properties of Materials Directly Associated with Erosion Damage," Wear, vol. 259, pp. 102-109, 2005.

[8] NFOFM, "Handbook of Multiphase FLow Metering," p. 30, 2005.

[9] B. S. McLaurry, "Modeling erosion in chokes," Proceeding of ASME Fluids Eng. Summer Meeting, 1996.

[10] ISO-14688-1, "Geotechnical Investigation and Testing - Identification and Classification of Soil," 2002.
[11] I. Finnie, "Erosion of Surfaces by Solid Particles," Wear, vol. 3, pp. 87-103, 1960.

[12] R. Durand and E. Condolios, "The hydraulic Transport of Coal and Solid Materials in Pipes," Laboratoire, 1952.

[13] N. P. Brown and N. I. Heywood, "Slurry Handling: Design of Solid-Liquid Systems," Essex: Elsevier Science Publishers LTD, p. 3, 1991.

[14] ANSYS, "ANSYS Help Viewer version 18.0," 2018.

[15] ANSYS, "ANSYS Fluent Suport," 2015. 